\title{
Remote Plasma Cleaning from a TEM Sample Holder with an Evactron ${ }^{\circledR}$ De-Contaminator
}

\author{
Christopher G. Morgan, David Varley, and Ronald Vane
}

XEI Scientific, Inc.

1755 E. Bayshore Rd., Suite 17

Redwood City, CA 94063

The Evactron ${ }^{\circledR}$ De-Contaminator (D-C), introduced in 1999, has been shown to be effective at removing hydrocarbon contamination from scanning electron microscopes (SEMs) [1].

Contamination results in poorer image quality, especially at high magnification and low beam voltage. The Evactron D-C works by placing an electrode in a small vacuum chamber and mounting this unit to the SEM chamber. Radio frequency (RF) plasma is generated at the electrode; room air or other oxygen containing gas is introduced into the SEM chamber and travels past the electrode, creating plasma and oxygen radicals. These radicals then travel through the SEM chamber and remove the hydrocarbons by chemical etch. The Evactron D-C operates between 0.05-1.0 Torr; this pressure range can be attained for limited periods by almost all SEMs. With minor changes to the vacuum system, longer clean times can be achieved. The Evactron $\mathrm{D}-\mathrm{C}$ is effective because the open geometry inside the SEM chamber allows the radicals to be carried by convection from the plasma throughout the chamber. Significant improvement in image quality has been seen with cleaning times of 10 minutes.

Transmission electron microscopes (TEMs) can also have their image quality affected by hydrocarbon contamination. However, when a conventional Evactron D-C is mounted on a TEM, the oxygen radicals are most likely produced a significant distance from the sample examination area most subject to contamination and requiring the most intensive cleaning. Also, the radicals will have to travel a more tortuous path than they would in the more open SEM chamber. These difficulties require that longer clean times be used, but the vacuum systems on TEMs often limit the ability to achieve this.

Horiuchi et al. reported a method to use an Evactron D-C in order to clean a TEM [2]. The authors mounted the Evactron D-C to a port on a TEM near sample examination region and an auxiliary pump to another port on the opposite the side of the TEM column. After 20 cycles of 3 minutes remote plasma cleaning and 3 minutes of nitrogen purge post cleaning, the authors were able to show that clearer TEM images could be obtained.

A new method for using the Evactron D-C to clean TEMs is reported here. The RF electrode used to create the oxygen radicals is now mounted on the end of a TEM sample rod. The impedance matching network and gas delivery hardware are placed on the other end of the sample rod, which is hollow to allow oxygen containing gas to reach the electrode. This configuration, a picture of which is shown in Figure 1, allows cleaning very near the sample examination region. The cleaning rate of the new Evactron D-C configuration was quantified using a quartz crystal microbalance (QCM) and compared to the standard configuration. This method of obtaining cleaning rates has been reported previously [3]. The results, seen in Figure 2, show that the cleaning rate for the Evactron D-C on the TEM sample rod at low power is comparable to the standard Evactron D-C at higher power. 


\section{References}

[1] A. Vladár, M. Postek and R. Vane, Proc. SPIE 4344 (2001) 835; N. Sullivan, T. Mai, S. Bowdoin and R. Vane, Micros. Microanal. 8 (Suppl 2) (2002) 720CD; P. Rolland, V. Carlino and R. Vane, Micros. Microanal. 10 (Suppl 2) (2004) 964CD; R. Vane and V. Carlino, Micros. Microanal. 11 (Suppl 2) (2005) 900

[2] S. Horiuchi, T. Hanada, M. Ebisawa, Y. Matsuda, M. Kobayashi and A. Takahara, ACS Nano, 2009, 3(5), 1297-1304

[3] M. M.Gleason, C. G. Morgan and R. Vane, Micros. Microanal. 13 (Suppl 2) (2007) 1734CD;

C. G. Morgan, M. M. Gleason and R. Vane, Micros. Microanal. 13 (Suppl 2) (2007) 1736CD

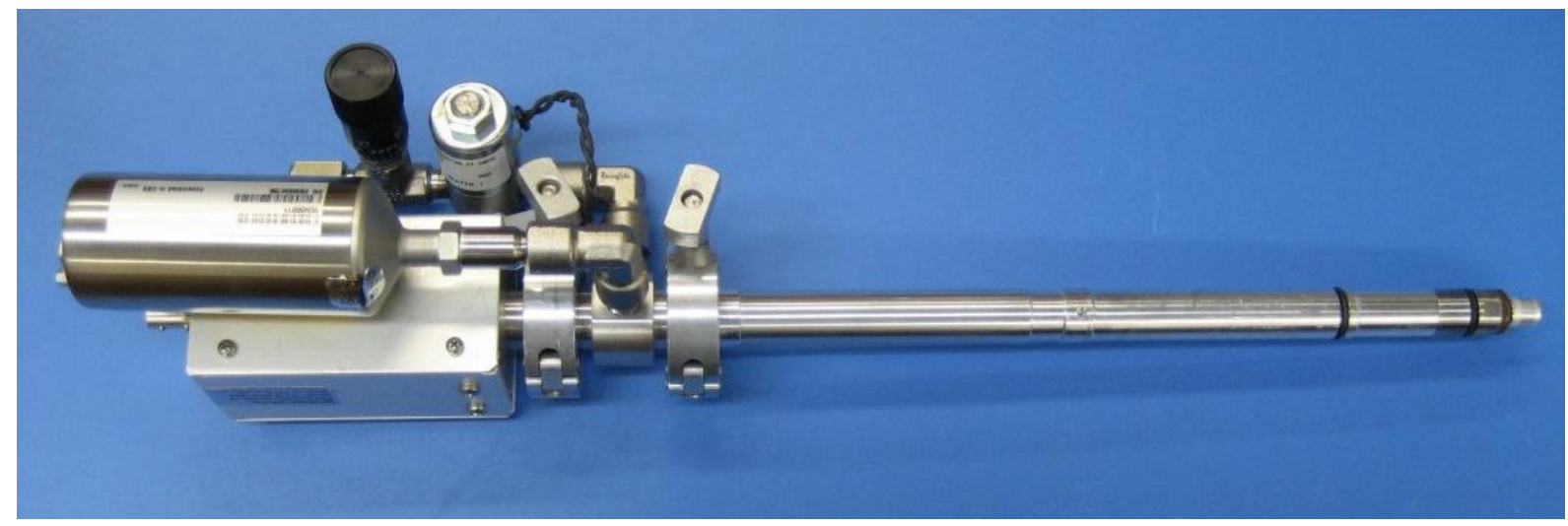

Fig. 1: Picture of the Oxygen Radical Source (ORS) on a TEM Holder. The RF electrode is on the right hand side near where a TEM sample would normally be. The valve assembly, pressure gauge and impedance match are on the left hand side of the picture.

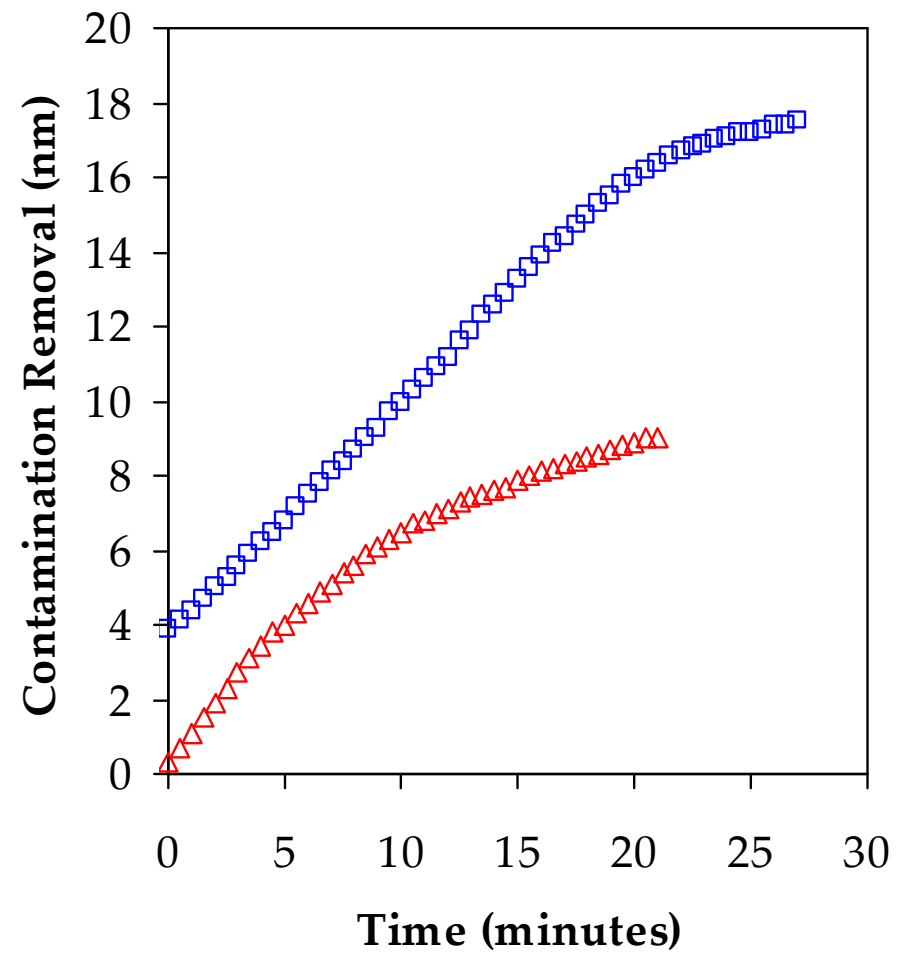

Fig.2: Removal of contamination from a QCM using the Evactron D-C. The triangles $(\Delta)$ were data taken using the Oxygen Radical Source (ORS) on a TEM Holder. Forward RF Power $=10 \mathrm{~W}$, the QCM was $9 \mathrm{~cm}$ from ORS and had a $\sim 8$ nm contamination layer. The squares $(\square)$ were data taken using the Standard ORS, Forward RF Power $=17 \mathrm{~W}$, the QCM was $15 \mathrm{~cm}$ from ORS and had a $\sim 13 \mathrm{~nm}$ contamination layer. 